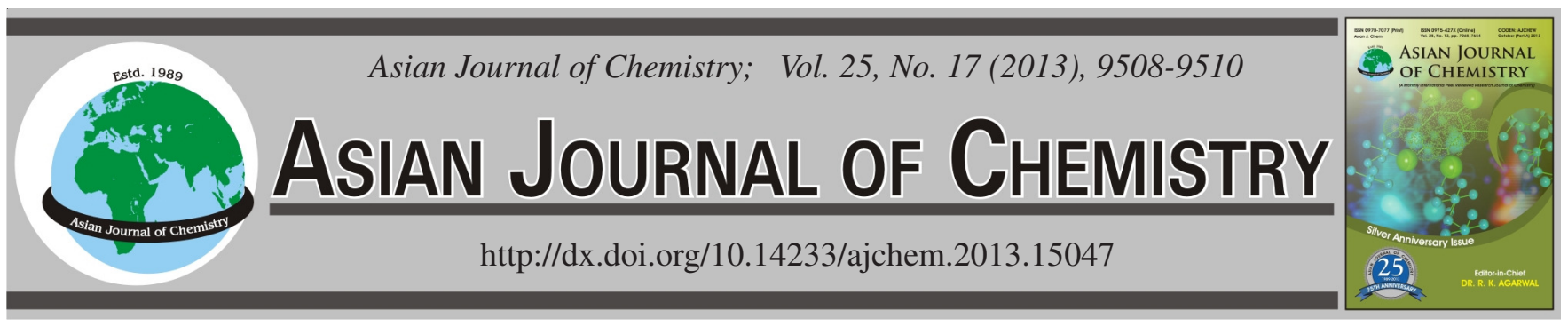

\title{
Kinetic Study of Methyl Orange Wastewater Degradation of Catalytic Wet Air Oxidation by Fe-Co Activated Carbon
}

\author{
Jinchuan Gu, Chunmei Wei*, Baojun Tan* and Ziliang Mei
}

Xihua University, Chengdu 610039, Sichuan Province, P.R. China

*Corresponding author: E-mail: wcmei2005@163.com

\begin{abstract}
Catalyst was prepared by the impregnation method using Fe-Co as active component, activated carbon as carrier. The sorption kinetics of methyl orange wastewater on Fe-Co activated carbon was investigated. The results indicate the catalytic wet air oxidation could be described using the first order kinetics, which was fitted well with the experimental data. It had a significant impact on the degradation rate that the dye of active component and the initial $\mathrm{ClO}_{2}$ concentration. Moreover, the lower activation energy of shows the reaction can be initiated easily.

Key Words: Methyl orange, Catalytic wet air oxidation, Active carbon, Fe-Co, Kinetics.
\end{abstract}

\section{INTRODUCTION}

Over the last decade, it has been shown that active carbons alone can act as efficient catalysts in catalytic wet air oxidation of non-biodegradable pollutants, such as phenol and phenolic compounds. Compared to most of the recently developed noble metal or metal oxide based catalysts, a commercial active carbon tested in a laboratory trickle bed reactor has demonstrated a similar or even better and stable activity for the catalytic wet air oxidation of phenol. The catalytic wet air oxidation of bio-toxic pollutants over active carbon becomes especially attractive for sequential adsorption-oxidation cycles or biological end-treatments. These combined processes generally perform a superior cleaning effectiveness compared to single step oxidation and avoid the need of complete organic pollutant mineralization in the catalytic wet air oxidation step. However, the knowledge of the intermediate distribution and its related biodegradability, which can be obtained from respirometry tests or ISO-standard is of relevance for the correct set-up of such combined chemical-biological treatment. Because of the importance of catalytic wet air oxidation and active carbon for the remediation of bio-toxic pollutants, the assessment of reliable kinetics (including intermediates) is required for the proper design, scale up and operation of catalytic wet air oxidation units. Batch oxidation studies of phenol over active carbon are very scarce and only phenol degradation has been considered. In case of phenolic compounds that show a high polymerization potential, liquid phase condensation reactions become important and fast deactivation of catalysts has been observed in batch oxidation, most likely due to the irreversible deposition of condensation products on the catalyst surface. Alternatively, a liquid full fixed-bed reactor with oxygen pre-saturated liquid feed has been operated at conversions smaller than $10 \%$ to avoid oxygen depletion. For phenol conversions of this magnitude, the progress of intermediate oxidation, however, cannot be satisfactorily monitored. To overcome this drawback, oxidation of phenol over active carbon has been studied in an integral fixed-bed reactor under reaction control and stable catalyst activity. Again, these works have only considered the destruction kinetics of phenol and lumped intermediates as COD or TOC.

The intermediate distribution and reaction pathway of phenol oxidation over active carbon or Fe active carbon has been studied conducting independent oxidation experiments. On the other hand, the detailed description of intermediate distribution is currently not reflected in the related kinetic modeling. Thus, this work focuses on advanced kinetic modeling to contrast the available experimental information of the oxidation route. The main difficulty in complex reaction systems is to obtain the numerous kinetic parameters involved.

\section{EXPERIMENTAL}

Preparation of catalysts: Active carbon was selected for a supported catalyst for this project, which has soaked for $4 \mathrm{~h}$ and then washed to remove all impurities. It was then dried overnight at $110^{\circ} \mathrm{C}$. Then different concentrations of mixtures were used to soak active carbon for $24 \mathrm{~h}$, filtered, putting in drying oven at $100{ }^{\circ} \mathrm{C}$ for $2 \mathrm{~h}$ and roasted. 
Catalytic wet air oxidation experiments: Catalytic wet air oxidation experiments are carried out at laboratory scale by first $50 \mathrm{~mL}$ methyl orange wastewater put into a $250 \mathrm{~mL}$ conical flask, then different constant concentration $\mathrm{ClO}_{2}(0.12-$ $0.96 \mathrm{~g} / \mathrm{L}$ ) and Fe-Co activated carbon (40-100 g/L) mixed solution was added in the conical flask.

\section{RESULTS AND DISCUSSION}

Catalyst load effect: Fig. 1 showed that when higher clay does is used the methyl orange degradation is obvious. This increment in the degradation occurs because when the amount of pillared clay catalyst increases, more $\mathrm{HO}^{\bullet}$ species are produced and are thus available for the oxidation reaction. After 90 min of reaction, the concentration of methyl orange decreases from $485.45 \mathrm{mg} / \mathrm{L}$ down to less than $1 \mathrm{mg} / \mathrm{L}$ when the catalyst concentration is raised from 40 to $100 \mathrm{mg} / \mathrm{L}$.

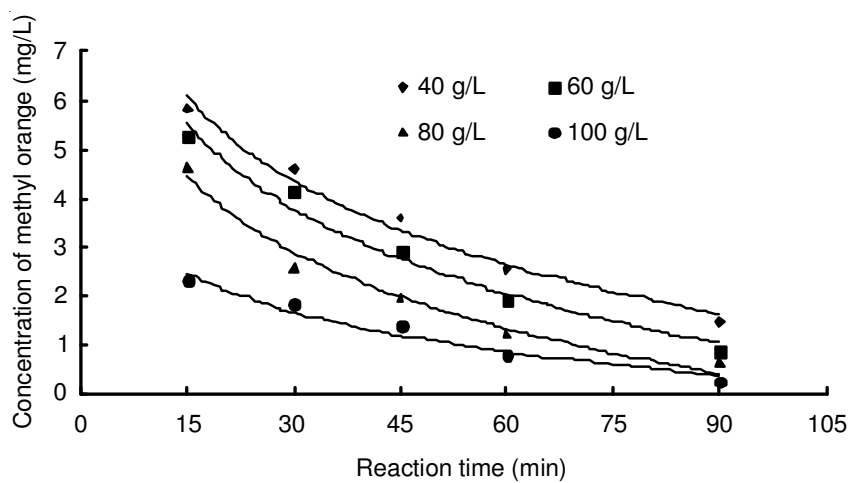

Fig. 1. Effect of catalyst adding amount on degradation of methyl orange

$\mathrm{ClO}_{2}$ concentration effect: In the wet air oxidation process, the oxidant concentration is a key factor that can significantly influence the organics degradation. Because the concentration effect $\mathrm{ClO}_{2}$ concentration is directly related to the number of hydroxyl radicals generated and thus to the performance achieved (Fig. 2).

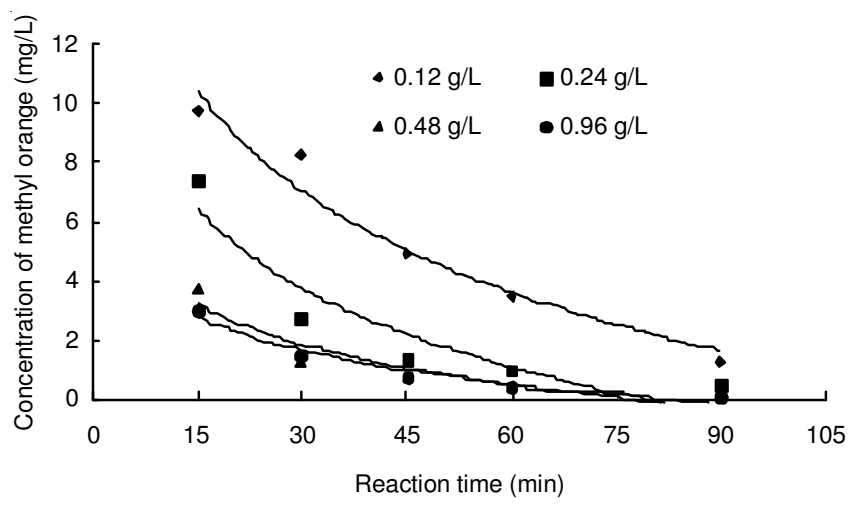

Fig. 2. Effect of initial $\mathrm{ClO}_{2}$ concentration on degradation of methyl orange

The results obtained show a similar behaviour in term o dye degradation for the intermediate $\mathrm{ClO}_{2}$ concentration, whereas the reaction goes by more slowly when the concentration is lower and faster when the concentration is higher. The crease of the oxidant concentration lead, to an increase in the reaction rate as expected, because more radicals will be formed.
Temperature effect: The results obtained for the methyl orange degradation at four different temperatures are shown in Fig. 3. It is evident that the concentration of methyl orange declines and the oxidation reaction accelerates when increasing the temperature, which was expected due to the exponential dependency of kinetic constants with the temperature.

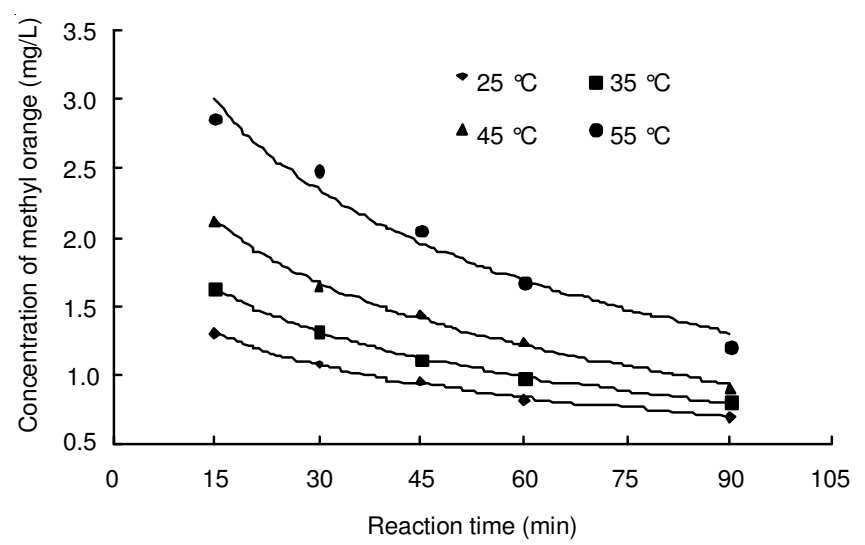

Fig 3. Effect of temperature on degradation of methyl orange

The performances of removal of methyl orange achieved at $25^{\circ} \mathrm{C}$ might be considered satisfactory. Although the process is not as fast as at higher temperatures. Taking into account that a lower temperature might reduce the process costs, $25^{\circ} \mathrm{C}$ was the temperature chosen to carry out the following runs, where the other parameters were changed.

Kinetic model: The mass balance in a slurry batch reactor yields:

$$
\frac{\mathrm{dC}}{\mathrm{dt}}=-\mathrm{KC}^{\mathrm{n}}
$$

where $\mathrm{C}$ represents the concentration of methyl orange, $\mathrm{K}$ is the reaction rate which $\mathrm{Fe}-\mathrm{Co}$ and $\mathrm{ClO}_{2}$ reacts in some temperature. The symbol $\mathrm{t}$ and $\mathrm{n}$ stands for reaction time and reaction order, respectively.

According to kinetic studies, the catalytic wet air oxidation is a first-order reaction. So the eqn. 1 can be used in the following form:

$$
\ln \left(\frac{\mathrm{C}}{\mathrm{C}_{0}}\right)=-\mathrm{Kt}
$$

when $\mathrm{t}=0$, the concentration of methyl orange is $\mathrm{C}_{0}=485.45$ $\mathrm{mg} / \mathrm{L}$ and the concentration of Fe-Co is $\mathrm{F}=\mathrm{F}_{0} \mathrm{mg} / \mathrm{L}$. The $\mathrm{K}$ can also show as following:

$$
\mathrm{K}=\mathrm{K}_{0}[\mathrm{~F}]_{0}^{\mathrm{p}}\left[\mathrm{ClO}_{2}\right]_{0}^{\mathrm{q}}
$$

The kinetic equation expressed in term of the eqn. 2 and eqn. 3 is following:

$$
\ln \left(\frac{\mathrm{C}}{\mathrm{C}_{0}}\right)=-\mathrm{k}^{\prime} \exp \left(\frac{\Delta \mathrm{E}}{\mathrm{RT}}\right)[\mathrm{F}]_{0}^{\mathrm{p}} \times\left[\mathrm{ClO}_{2}\right]_{0}^{\mathrm{q}} \mathrm{t}
$$

To solve $\mathrm{P}$, reaction rate equation $\mathrm{K}$ of methyl orange must be first obtained based on Fig. 1 that a linear fitting to the $\ln \left(C / C_{0}\right)$-t curve was carried out, then it is obtained that the plots of $\ln \mathrm{K}$ versus $\ln [\mathrm{F}]$ are given a straight line with the line with the slope, from these data it can calculate the $p=0.5033$. 
To solve $\mathrm{q}$, take logarithm value of $\mathrm{K}$ as $\mathrm{X}$-axis, logarithm value of the concentration of $\mathrm{ClO}_{2}$ as Y-axis, the slope of straight line was $\mathrm{q}=0.2273$.

To solve $\Delta \mathrm{E}$ and $\mathrm{k}^{\prime}$, take logarithm value of $\mathrm{K}$ as $\mathrm{X}$-axis, reciprocal value of $\mathrm{T}$ as $\mathrm{Y}$-axis, the slope of straight line was $\mathrm{q}$ $=0.2273$ and the intercept of straight line was $\mathrm{k}^{\prime}=0.28$.

So, dynamical model on the degradation of metyl orange by catalytic wet air oxidation was following:

$$
-\ln \left(\frac{\mathrm{C}}{\mathrm{C}_{0}}\right)=0.28 \exp \left(-\frac{10347.60}{\mathrm{RT}}\right)[\mathrm{F}]_{0}^{0.5033} \times\left[\mathrm{ClO}_{2}\right]_{0}^{0.2273} \mathrm{t}(5)
$$

\section{Conclusion}

The catalytic wet oxidation using Fe-Co activated carbon as catalyst is a promising technique for the treatment of these types of wastewater; activated carbon is quite active in both the oxidation and mineralization of this wastewater. It is chemically stable during long periods of time, on streams at the operational conditions used in this work.

It was possible to establish simple kinetic laws that appear to be in satisfactory agreement with the experimental rats observed. The order with respect to the dye of active component and the initial $\mathrm{ClO}_{2}$ concentration was found to be one in all cases. This study reports these elements order dependence on degradation rate. The dye of active component was more important than initial $\mathrm{ClO}_{2}$ concentration. So if the dye of active component was optimal, the degradation rate was better.

\section{ACKNOWLEDGEMENTS}

The project is supported by Ministry of Education Chunhui Project No. Z201199 and No. Z2011100 and Educational Commission of Sichuan Province No. 12204440.

\section{REFERENCES}

1. A. Eftaxias, J. Font, A. Fortuny, A. Fabregat and F. Stuber, Appl. Catal. B: Environ., 67, 12 (2006).

2. J. Garicia, H.T. Gomes, P. Serp, P. Kalck, J.L. Figueiredo and J.L. Faria, Catal. Today, 102 (2005).

3. A. Pintar, G. Bercic, M. Besson and P. Gallezot, Appl. Catal. B: Environ., 47, 143 (2004).

4. F. Arena, C. Italiano, A. Raneri and C. Saja, Appl. Catal. B: Environ., 99, 321 (2010).

5. B.X. Zhao, B.C. Shi, X.L. Zhang, X. Cao and Y.Z. Zhang, Desalination, 268, 55 (2011).

6. P. Massa, F. Lvorra, P. Haure, F.M. Cbello and R. Fenoglio, Catal. Commun., 8, 424 (2007).

7. S. Kim and D. Lee, Catal. Today, 97, 153 (2004).

8. L.X. Li, P.S. Chen and E.F. Gloyna, J. AIChE, 37, 1687 (1991).

9. A. Santos, P. Yustos, S. Gomis, G. Ruiz and F. Garcia-Ochoa, Chem. Eng. Sci., 61, 2457 (2006).

10. G. Deiber, J.N. Foussard and H. Debellfontaine, Environ. Pollut., 96, 311 (1997).

11. S. Lefevre, O. Boutin, J.-H. Ferrasse, L. Malleret, R. Faucherand and A. Viand, Chemosphere, 84, 1208 (2011).

12. J. Herney-Ramirez, A.M.T. Silva, M.A. Vicente, C.A. Costa and L.M. Madeira, Appl. Catal. B: Environ., 101, 197 (2011).

13. E.V. Rokhina, E. Repo and J. Vrkutyte, Ultrason. Sonochem., 17, 541 (2010) 